\title{
Short Report: Use of a Rapid Test on Umbilical Cord Blood to Screen for Trypanosoma cruzi Infection in Pregnant Women in Argentina, Bolivia, Honduras, and México
}

\begin{abstract}
Sergio Sosa-Estani,* Miriam Rubi Gamboa-León, Jaime del Cid-Lemus, Fernando Althabe, Jackeline Alger, Olivia Almendares, María L. Cafferata, Jean-Philippe Chippaux, Eric Dumonteil, Luz Gibbons, Nicolás Padilla-Raygoza, Dominique Schneider, José M. Belizán, Pierre Buekens, and Working Group Instituto de Efectividad Clínica y Sanitaria, Centro Nacional de Diagnóstico e Investigación de Endemoepidemias (CeNDIE) ANLIS Dr. Carlos G. Malbrán, Ministerio de Salud, Buenos Aires, Argentina; Región Departamental de Salud de Intibucá, La Esperanza, Intibucá, Honduras; Instituto de Enfermedades Infecciosas y Parasitología Antonio Vidal, Tegucigalpa, Honduras; Laboratorio de Parasitología, Centro de Investigaciones Regionales "Dr. Hideyo Noguchi", Universidad Autónoma de Yucatán, Mérida, Yucatán, México; Facultad de Enfermería y Obstetricia de Celaya, Universidad de Guanajuato, Celaya, Guanajuato, México; Research Unit 'Mother and Child Health in the Tropics', Institut de Recherche pour le Développement, La Paz, Bolivia; Laboratorio de Parasitología, Instituto Nacional de Laboratorios de Salud, La Paz, Bolivia; Unidad de Investigación Clínica y Epidemiológica Montevideo, Montevideo, Uruguay; School of Public Health and Tropical Medicine, Tulane University, New Orleans, Louisiana
\end{abstract}

Abstract. We conducted a cross-sectional study of Chagas disease in five endemic areas in Argentina, Bolivia, Honduras, and México to estimate the prevalence of Trypanosoma cruzi-specific antibodies in pregnant women, and to assess the use of a rapid test (Chagas Stat-Pak) to screen for T. cruzi infection at the time of delivery. The prevalence of antibodies to T. cruzi measured by enzyme-linked immunosorbent assay (ELISA) in maternal blood was $5.5 \%$ (a range of $0.8-28.8 \%$ among the countries) in 2,495 women enrolled. Compared with ELISA in maternal blood samples, the Chagas Stat-Pak rapid test sensitivity and specificity in umbilical cord blood were $94.6 \%$ and $99.0 \%$, respectively. These results show the ability for a rapid determination of the presence of $T$. cruzi-specific antibodies in umbilical cord blood as a pragmatic strategy to screen for infection in pregnant women.

Chagas disease, or American Trypanosomiasis, is caused by the protozoan parasite Trypanosoma cruzi. It is a major cause of morbidity and mortality in Latin America. Infection is transmitted mainly by vectors, but also by transfusion of infected blood or congenital transmission from a mother to her fetus. ${ }^{1}$ A strategy to identify maternal infection at delivery will be an asset to select children needing care. Umbilical cord blood is readily available for testing among women delivering in health facilities, and avoids additional venipuncture of the mother. However, the placental transfer of maternal antibodies is not straightforward and can be reduced by infections as described for malaria. ${ }^{2}$ Meanwhile, others showed an opposite phenomena during $T$. cruzi infection. ${ }^{3,4}$ Furthermore, the mechanisms of maternal antibody transfer are still not fully understood in the case of Chagas disease, ${ }^{5}$ and it would be important to evaluate and confirm the usefulness of detecting maternal T. cruzi antibodies in cord blood. We conducted a study in selected Latin American countries with different T. cruzi endemic situations. Our aims were: 1) to estimate the prevalence of antibodies to $T$. cruzi in pregnant women; and 2) to assess the accuracy of a rapid test (Chagas Stat-Pak, Chembio Diagnostic Systems, Medford, NY) for screening $T$. cruzi infection in pregnant women using umbilical cord blood.

We performed a cross-sectional descriptive study in five hospitals in endemic areas of $T$. cruzi infection in four countries: Instituto Maternidad Provincial "Nuestra Señora de las Mercedes" in Tucumán, Argentina; Instituto Maternológico Percy Boland in Santa Cruz, Bolivia; Hospital Enrique Aguilar Cerrato in Intibucá, Honduras; Hospital Materno-Infantil

\footnotetext{
* Address correspondence to Sergio Sosa-Estani, Instituto de Efectividad Clínica y Sanitaria, and Centro Nacional de Diagnóstico e Investigación de Endemoepidemias (CeNDIE) ANLIS "Dr. Carlos G. Malbrán,” Av. Paseo Colón 568 (1063), Buenos Aires, Argentina. E-mail: ssosa@msal.gov.ar
}

in Mérida, Yucatán; and Hospital General in Celaya, Guanajuato in México. Study participants were women presenting for delivery between September 2006 and February 2007 and their newborns. Women $\geq 18$ years of age at the time of delivery, having single live births, were invited to participate. Maternal and umbilical cord blood samples were obtained from each woman who accepted to participate in the study and signed an informed consent.

Enzyme-linked immunosorbent assay (ELISA) on both maternal and umbilical cord blood samples was performed according to the manufacturer's instructions for the determination of antibody levels in plasma (Chagatest ELISA recombinant, version 3.0; Wiener Laboratories, Rosario, Argentina). ${ }^{6}$ Whole blood of maternal and umbilical cord blood samples were also tested by the Chagas Stat-Pak, which is a rapid immunochromatographic screening test for detection of anti-T. cruzi antibodies in whole blood and serum. ${ }^{7,8}$ External quality control of ELISA was performed by a central reference laboratory (Wiener Laboratory, Buenos Aires, Argentina) on all positive samples and $10 \%$ of the negative samples from Tucumán, Intibucá, Celaya, and Mérida.

Clinical and socio-demographic data were obtained by clinical records or by interviewing the mothers during their hospital stays. All data, including test results, digital photographs of the Chagas Stat-Pak cassette (at 15 minutes of reaction time), and ELISA optical density readouts, were sent by encrypted e-mail to the data center (Unidad de Investigación Clínica y Epidemiológica, Montevideo, Uruguay) for storage and double data entry into a secure data management system.

The maternal prevalence of $T$. cruzi-specific antibodies by site was reported as the prevalence of ELISA sero-reactive women with $95 \%$ confidence intervals (95\% CI). We also calculated the sensitivity (Se), specificity (Sp), accuracy (Ac), and positive and negative predictive values (PPV and NPV) of Chagas Stat-Pak in umbilical cord samples in comparison 

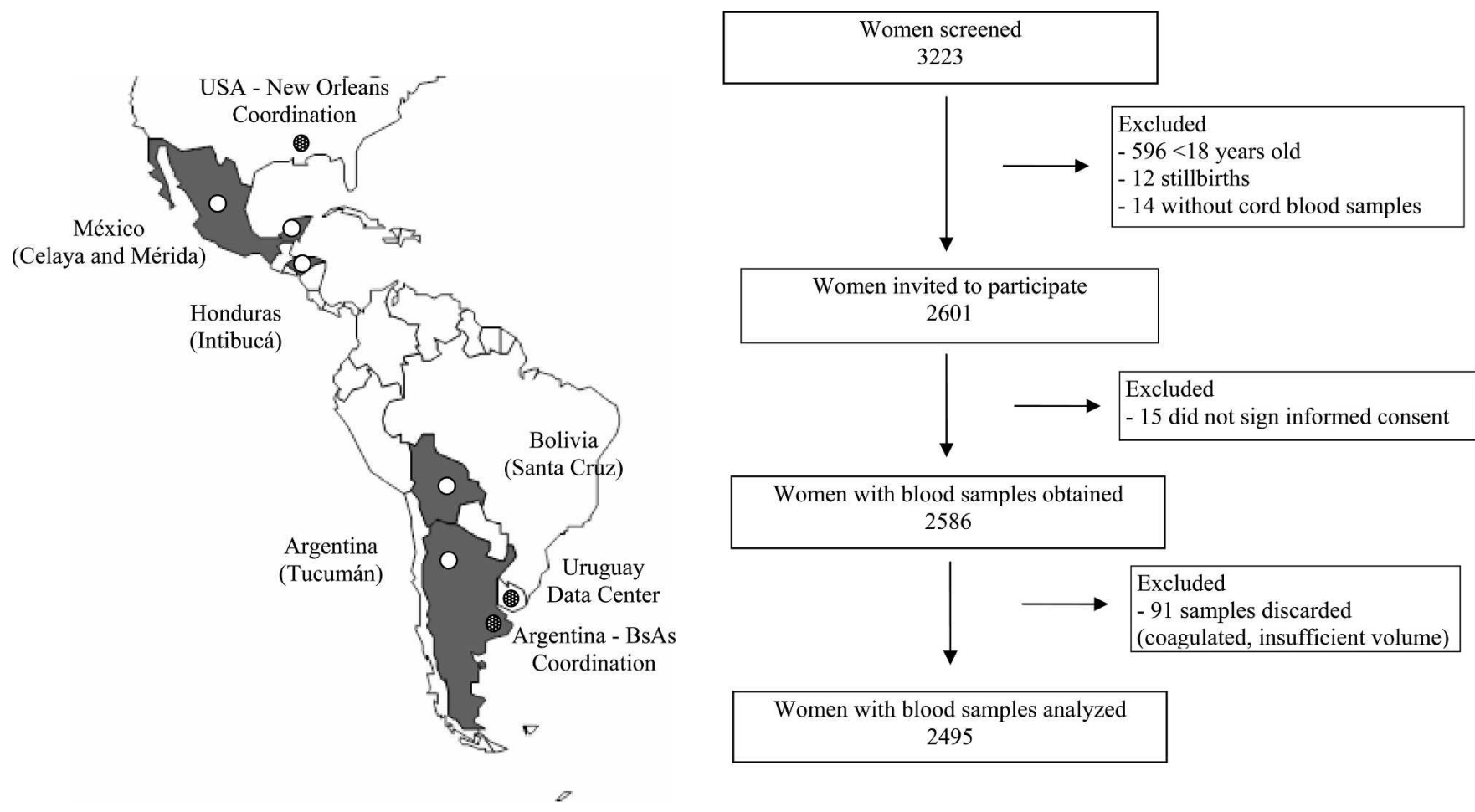

Figure 1. Study sites and flowchart of recruitment. Argentina, Bolivia, Honduras, and México, 2006-2007.

with maternal blood using ELISA as the gold standard, with their respective exact binomial $95 \%$ CI. A sample size of 500 women per site provided a $95 \%$ precision rate of $\pm 2 \%$ if the prevalence was $6 \%$. All tests and procedures were standardized in all sites. The analyses were done using SPSS version 14.0 (SPSS, Chicago, IL) and Epi Info version 3.4 (CDC).

The study was approved by the Institutional Review Board of Tulane University and the ethics committees of the respective participating institutions. Newborns from mothers confirmed positive for T. cruzi infection were referred for appropriate clinical follow-up and treatment if needed, according to the established local practices at each site.

Among 2,495 female participants (Figure 1), the distribution of population by site was 518 women in Tucumán, 488 in Santa Cruz, 500 in Intibucá, and 988 in Celaya and Mérida. The mean age was $25.3 \pm 6.0$ years. Among total women enrolled in the study, 205 volunteers were positive by ELISA for antibodies to T. cruzi infection, yielding a median of prevalence of $5.5 \%$. The seroprevalence rate was heterogeneous between countries; the highest rate was observed in Santa Cruz (Bolivia) (28.8\%), followed by Tucumán (Argentina) (6.6\%),
Intibucá (Honduras) (4.4\%), and Celaya and Mérida (México) (0.8\%) (Table 1). The absorbance of T. cruzispecific antibodies in maternal samples assayed by ELISA showed a strong correlation with that of umbilical cord samples $(\mathrm{r}=0.986)$. Concordance among ELISA and Chagas Stat-Pak for maternal and umbilical cord samples were $98 \%$ $(\mathrm{CI}=97.5-96.6)$ and 98.6\% (CI $=98.1-99.1)$, respectively. At most sites, the prevalence from samples tested by Chagas Stat-Pak in cord blood were in close agreement with the rates obtained with the gold standard (ELISA in maternal blood). Only results from Intibucá (Honduras) showed a significant difference between maternal rates using ELISA and umbilical cord samples using Stat-Pak $(P<0.01)$, (Table 1$)$. Overall, the performance of the Chagas Stat-Pak for detection of anti- $T$. cruzi antibodies in umbilical cord samples in comparison with the gold standard showed values of $94.6 \%$ Se; $99 \% \mathrm{Sp} ; 98.6 \%$ Ac; $89 \% \mathrm{PPV}$; and $99.5 \% \mathrm{PNV}$. Test performance varied among countries (Table 2).

All sites used a standardized methodology to collect data and samples, which allowed us to reduce internal bias. However, the results presented in this study have some limitations,

TABLE 1

Prevalence of antibodies against Trypanosoma cruzi detected among 2,495 pregnant women and their newborns tested by ELISA and Chagas Stat-Pak, from Argentina, Bolivia, Honduras, and México, 2006-2007

\begin{tabular}{|c|c|c|c|c|c|c|c|c|c|c|}
\hline & \multicolumn{2}{|c|}{$\begin{array}{l}\text { Tucumán (Argentina) } \\
\qquad(N=518)\end{array}$} & \multicolumn{2}{|c|}{$\begin{array}{c}\text { Santa Cruz (Bolivia) } \\
(N=488)\end{array}$} & \multicolumn{2}{|c|}{$\begin{array}{l}\text { Intibucá (Honduras) } \\
\quad(N=500)\end{array}$} & \multicolumn{2}{|c|}{$\begin{array}{l}\text { Celaya and Mérida (México) } \\
\qquad(N=988)^{*}\end{array}$} & \multicolumn{2}{|c|}{$\begin{array}{c}\text { Total } \\
(N=2,495)\end{array}$} \\
\hline & $\mathrm{n}$ & $\%(95 \% \mathrm{CI})$ & $\mathrm{n}$ & $\%(95 \% \mathrm{CI})$ & $\mathrm{n}$ & $\%(95 \% \mathrm{CI})$ & $\mathrm{n}$ & $\%(95 \% \mathrm{CI})$ & $\mathrm{n}$ & $\%(95 \%$ CI $)$ \\
\hline $\begin{array}{l}\text { Reactive ELISA in } \\
\text { maternal blood samples }\end{array}$ & 34 & $6.6(4.7-9.1)$ & 141 & $28.8(24.9-33.1)$ & 22 & $4.4(2.8-6.7)$ & 8 & $0.8(0.4-1.7)$ & 205 & $8.2(7.2-9.4)$ \\
\hline $\begin{array}{l}\text { Reactive Stat-Pak in } \\
\text { cord blood samples }\end{array}$ & 32 & $6.2(4.3-8.7)$ & 144 & $29.4(25.5-33.7)$ & 33 & $6.6(4.7-9.2)$ & 9 & $0.9(0.4-1.8)$ & 218 & $8.7(7.7-9.9)$ \\
\hline
\end{tabular}


TABLE 2

Detection of Trypanosoma cruzi-specific antibodies in cord blood samples tested by a Chagas Stat-Pak rapid test in comparison with the maternal blood samples tested by ELISA, among 2,495 pregnant women from Argentina, Bolivia, Honduras, and México, 2006-2007

\begin{tabular}{|c|c|c|c|c|c|c|c|c|c|c|}
\hline \multirow{2}{*}{$\begin{array}{l}\text { Umbilical cord samples tested } \\
\text { by Stat-Pak in comparison with } \\
\text { maternal blood samples tested by ELISA }\end{array}$} & \multicolumn{2}{|c|}{$\begin{array}{l}\text { Tucumán (Argentina) } \\
\qquad(N=518)\end{array}$} & \multicolumn{2}{|c|}{$\begin{array}{c}\text { Santa Cruz (Bolivia) } \\
(N=488)\end{array}$} & \multicolumn{2}{|c|}{$\begin{array}{l}\text { Intibucá (Honduras) } \\
\qquad(N=500)\end{array}$} & \multicolumn{2}{|c|}{$\begin{array}{l}\text { Celaya and Mérida (México) } \\
\qquad(N=988)\end{array}$} & \multicolumn{2}{|c|}{$(N \stackrel{\text { Total }}{=2,495)}$} \\
\hline & $\%$ & {$[95 \% \mathrm{CI}]$} & $\%$ & {$[95 \% \mathrm{CI}]$} & $\%$ & {$[95 \% \mathrm{CI}]$} & $\%$ & {$[95 \% \mathrm{CI}]$} & $\%$ & {$[95 \% \mathrm{CI}]$} \\
\hline Sensitivity & 85.3 & {$[71.9 ; 98.7]$} & 98.6 & {$[96.3 ; 100.0]$} & 95.4 & {$[84.5 ; 100.0]$} & 62.5 & {$[22.7 ; 100.0]$} & 94.6 & {$[91.3 ; 98.0]$} \\
\hline Specificity & 99.4 & {$[98.6 ; 100.0]$} & 98.6 & {$[97.2 ; 100.0]$} & 97.5 & {$[96.0 ; 99.0]$} & 99.6 & {$[99.2 ; 100.0]$} & 99.0 & {$[98.5 ; 99.4]$} \\
\hline Accuracy & 98.5 & {$[97.3 ; 99.61]$} & 98.6 & {$[97.4 ; 99.7]$} & 97.4 & {$[95.9 ; 98.9]$} & 99.3 & {$[98.7 ; 99.9]$} & 98.6 & {$[98.1 ; 99.1]$} \\
\hline Positive predictive value & 90.6 & {$[79.0 ; 100.0]$} & 96.5 & {$[93.2 ; 99.9]$} & 63.6 & {$[45.7 ; 81.6]$} & 55.6 & {$[17.5 ; 99.5]$} & 89.0 & {$[84.6 ; 93.4]$} \\
\hline Negative Predictive value & 99.0 & {$[98.0 ; 100.0]$} & 99.4 & {$[98.5 ; 100.0]$} & 99.8 & {$[99.3 ; 100.0]$} & 99.7 & {$[99.3 ; 100.0]$} & 99.5 & {$[99.2 ; 99.8]$} \\
\hline
\end{tabular}

such as the pregnant women who participated may not be representative of pregnant women among the general population. Furthermore, participating hospitals were not randomly selected from among other hospitals in the country or study area, and only women older than 17 years of age were enrolled. For this reason, our results are restricted to women older than 17 years of age that sought care in the study sites selected for convenience. We also lost precision for the estimation of prevalence in Mexico and Honduras, because the measured prevalence was unexpectedly lower than that used for the sample size calculation, which was based on previous estimates of seroprevalence. ${ }^{9}$ The external quality control of ELISA in maternal blood samples showed Kappa indexes of $0.83,0.97$, and 0.93 in Tucumán, Intibucá, and Celaya and Mérida, respectively $(P<0.05)$.

Our study recruited women from five sites with some differences in socio-demographic characteristics, such as age, formal education level, and residence in urban or rural areas (data not shown). Differences in the characteristics of the study area, ${ }^{10-12}$ the dynamics of vectorial transmission, ${ }^{13,14}$ the history of programs for the control and prevention of vectorial and non-vectorial transmission in each country, ${ }^{15-23}$ and interstrain variability of $T$. cruzi may be additional factors to consider when interpreting differences in prevalence.

The Chagas Stat-Pak has been found to be appropriate for screening asymptomatic $T$. cruzi infection in a rapid assessment of schoolchildren. ${ }^{7,8}$ However, a field evaluation in children and adolescents from Bolivia has shown lower sensitivity. ${ }^{24}$ Our results have shown that the Chagas Stat-Pak was able to detect maternal antibodies in umbilical blood samples. However, its sensitivity was heterogeneous among countries.

Some of the potential explanations for this finding include: 1) Differences in levels of $T$. cruzi-specific antibodies in maternal samples in comparison with umbilical samples. The correlation of the absorbance of specific antibodies in maternal and umbilical cord blood samples were $0.98,0.54$, and 0.05 for concordant samples, ELISA reactive and Stat-Pak not reactive, and ELISA not reactive and Stat-Pak reactive, respectively. These results suggest that in some cases, differences in antibody concentrations in umbilical cord can affect the ability of Stat-Pak to detect it. 2) A different type of antigen used in the assays, $;{ }^{6,7}$ however, our data do not permit us to clarify this issue. The lower sensitivity of the rapid test in Mexico could be the result of poor detection by the antigens used in the test to the specific immune response induced for the autochthonous strain of parasites. 3) Technical errors while performing or reading the tests. Although the Chagas Stat-Pak test is easy to perform, it uses a visual inspection of bands, which may depend on the subjectivity of the operator. $^{7,8}$ The results in the external quality control show that the validation of the Stat-Pak assay can be affected by the variable performance of the ELISA gold standard at the different study sites.

We have shown in this pilot study a pragmatic strategy using umbilical cord samples and a rapid test to screen $T$. cruzi infection in pregnant women, which permits assessment of results in minutes and would be convenient in primary health care settings. Other large-scale studies would be necessary to confirm the viability of the strategy and to assess cost-effectiveness and acceptability. The potential use of this strategy is based on the fact that the collection of cord blood samples is done routinely in several countries for perinatal screening, including all participating sites, as part of perinatal care, making this proposed strategy even more viable.

Research about the risk of congenital T. cruzi infection and the effective detection of infected newborns is essential, because it is recognized as a major cause of transmission in nonendemic countries and endemic countries with relatively successful vector control and blood screening programs. ${ }^{15,25-28}$ The elimination of congenital $T$. cruzi infection will be a critical final step toward the elimination of Chagas disease, after elimination of transmission by vectors and blood transfusion.

Received March 27, 2008. Accepted for publication August 1, 2008.

Acknowledgments: The authors thank the following professionals and technicians from the Unidad de Investigación Clínica y Epidemiológica Montevideo for designing the Manual of Operations and for conducting the study data management: Alvaro Ciganda, Marcelo Delgado, and Federico Lachs. Colleagues from Tucumán-Argentina: Ricardo Durango (Resident), Jorge Carranza (Resident), Sebastian Diaz (Technician), Viviana Suarez (Biochemist), Maria Alba Brizuela (Statistics Section), Natalia Tesseira (Assistant), and personnel of the Delivery Ward and Surgical Room from Instituto Maternidad Provincial "Nuestra Sra de las Mercedes." Colleagues from Bolivia: Nadin Alejandra Salas-Clavijo, Mario Romero, Mercedes Galarza, Patricia Oporto, Tatiana Rios, and personnel of Hospital Percy Boland de Santa Cruz. Colleagues from Honduras: personnel from the Labor Unit and Surgical Room and Guillermo Casco (Laboratory Technologist) from Enrique Aguilar Cerrato Hospital, Intibucá; Renato Valenzuela from Instituto Antonio Vidal, Tegucigalpa. Colleagues from Celaya-México: Adriana Plascencia (Technician), Isabel Gutiérrez. Colleagues from Merida-México: Professional of Hospital Materno Infantil of Yucatan and a special thanks to Dr. Luis Roberto Cardenas Hernandez (Director of Maternity), Dr. Benito Argaez Tuz, Chief of Training of Maternity and to the medical student Claudia González Ramírez. The authors thank Andrea Lee Meyer from the SPHTM at Tulane University for her assistance in technical matters, the administrative personnel from the Institute for Clinical Effectiveness and Health Policy, Buenos Aires, Argentina. We are also grateful to Dr. Yves Carlier and Dr. Elsa Leonor Segura for critical review of the manuscript and their suggestions.

Other members of the Perinatal Chagas Disease Working Group include, from the United States: M. James (School of Public Health and Tropical Medicine), Tulane University; from Argentina: G. Gar- 
barino, R. Chahla (Instituto de Maternidad, Tucumán, Argentina); from Bolivia: J.R. Postigo-Ignacio, J. Santalla (Laboratorio de Parasitologia, Instituto Nacional de Laboratorios de Salud, La Paz, Bolivia); from Honduras: D. Amador (Hospital Enrique Aguilar Cerrato, Intibucá), I. Giron (Region Departamental de Salud, Intibucá), C. Ponce and E. Ponce (Laboratorio de Referencia para la Enfermedad de Chagas, Ministry of Health), and C. Zuniga (Programa Nacional de Prevención y Control de la Enfermedad de Chagas, Ministry of Health); from México: C. Gonzalez-Ramirez (Centro de Investigaciones Regionales "Dr. Hideyo Noguchi," Universidad Autónoma de Yucatán, Mérida, Yucatán, México)

Financial support: This project was supported by the Tulane University School of Public Health and Tropical Medicine, with partial support provided by the Institute for Clinical Effectiveness and Health Policy in Buenos Aires, Argentina, IRD (France), and the local Health Systems of each country (Argentina, Bolivia, Honduras and México). This study was funded in part by the National Institutes of Health Fogarty International Center grant number D43 TW007784. We are grateful to Chembio, New York for having provided initial samples of Chagas Stat-Paks and Wiener Lab, Rosario, Argentina for having provided all reagents necessary to perform the ELISA tests and for conducting the quality control of serologic diagnoses.

Authors' addresses: Sergio Sosa-Estani, Instituto de Efectividad Clínica y Sanitaria, and Centro Nacional de Diagnóstico e Investigación de Endemoepidemias (CeNDIE) ANLIS Dr. "Carlos G. Malbrán," Av. Paseo Colón 568 (1063), Buenos Aires. Argentina, Tel: 54-114331-4010, Fax: 54-11-4331-2536, E-mail: ssosa@msal.gov.ar. Miriam Rubi Gamboa-León and Eric Dumonteil, Laboratorio de Parasitología, Centro de Investigaciones Regionales "Dr. Hideyo Noguchi," Universidad Autónoma de Yucatán, Ave. Itzaés \#490 × 59, CP 97000, Mérida, Yucatán, México, Tel: 52-999-9245910, Fax: 52-999-9236120, E-mails: gleon@uady.mx and oliver@uady.mx. Jaime del Cid-Lemus, Región Sanitaria No. 10, Barrio El Centro, La Esperanza, Intibucá, Honduras, Tel: 504-7830046, E-mail: jaimedelcid@gmail.com. Fernando Althabe, Luz Gibbons, and José Belizán, Instituto de Efectividad Clínica y Sanitaria, Viamonte 2146 (1056), Buenos Aires, Argentina, Tel/Fax: 54-11-4-953-4058, E-mails: althabef@gmail.com, belizanj@allstat.org, and lgibbons@iecs.org.ar. Jackeline Alger, Instituto de Enfermedades Infecciosas y Parasitología Antonio Vidal, P.O. Box 6177, Tegucigalpa, Honduras, E-mail: malaria@cablecolor.hn. Olivia Almendares and Pierre Buekens, School of Public Health and Tropical Medicine, Tulane University, 1440 Canal Street, Suite 2430, New Orleans, LA 70112, Tel: 504-988-5397, Fax: 504-988-5718,E-mails: olivia.margarita@ gmail.com and pbuekens@tulane.edu. María Luisa Cafferata, Unidad de Investigación Clínica y Epidemiológica Montevideo, Hospital de Clínicas, Piso 15, Av. Italia s/n, Montevideo CP11600, Montevideo, Uruguay, Tel/Fax: 598-2-486-4175, E-mail: cafferam@gmail.com. Jean-Philippe Chippaux and Dominique Schneider, IRD, CP 9214, La Paz Bolivia, Tel: 591-2-222-1901, E-mails: chippaux@ird.fr and dschneider@club-internet.fr. Nicolás Padilla-Raygoza, Mutualismo \#303, CP 38060, Apdo. Postal 91 Celaya, Guanajuato, México, Tel: 52-461-615-36-48, Fax: 52-461-615-36-65, E-mail: padillawarm@ gmail.com.

\section{REFERENCES}

1. World Health Organization, 2002. Report of the Expert Committee on the Control of Chagas Disease. Geneva: World Health Organization, 115.

2. Cumberland P, Shulman CE, Maple PA, Bulmer JN, Dorman EK, Kawuondo K, Marsh K, Cutts FT, 2007. Maternal HIV infection and placental malaria reduce transplacental antibody transfer and tetanus antibody levels in newborns in Kenya. $J$ Infect Dis 196: 550-557.

3. Lorca M, Veloso C, Munoz P, Bahamonde MI, Garcia A, 1995. Diagnostic value of detecting specific IgA and IgM with recombinant Trypanosoma cruzi antigens in congenital Chagas' disease. Am J Trop Med Hyg 52: 512-515.

4. Truyens $C$, Hermann E, Alonso-Vega C, Rodriguez P, Vekemans J, Torrico F, Carlier Y, 2005. Immune responses of noninfected neonates of mothers infected with Trypanosoma cruzi. Rev Soc Bras Med Trop 38 (Suppl 2): 96-100.

5. Lin S, Sartori MJ, Mezzano L, de Fabro SP, 2005. Placental al- kaline phosphatase (PLAP) enzyme activity and binding to IgG in Chagas' disease. Placenta 26: 789-795.

6. Caballero ZC, Sousa OE, Marques WP, Saez-Alquezar A, Umezawa ES, 2007. Evaluation of serological tests to identify Trypanosoma cruzi infection in humans and determine crossreactivity with Trypanosoma rangeli and Leishmania spp. Clin Vaccine Immunol 14: 1045-1049.

7. Luquetti AO, Ponce C, Ponce E, Esfandiari J, Schijman A, Revollo S, Anez N, Zingales B, Ramgel-Aldao R, Gonzalez A, Levin MJ, Umezawa ES, Franco da Silveira J, 2003. Chagas' disease diagnosis: a multicentric evaluation of Chagas StatPak, a rapid immunochromatographic assay with recombinant proteins of Trypanosoma cruzi. Diagn Microbiol Infect Dis 46 : 265-271.

8. Ponce C, Ponce E, Vinelli E, Montoya A, de Aguilar V, Gonzalez A, Zingales B, Rangel-Aldao R, Levin MJ, Esfandiari J, Umezawa ES, Luquetti AO, da Silveira JF, 2005. Validation of a rapid and reliable test for diagnosis of Chagas' disease by detection of Trypanosoma cruzi-specific antibodies in blood of donors and patients in Central America. J Clin Microbiol 43: 5065-5068.

9. Cruz-Reyes A, Pickering-Lopez JM, 2006. Chagas disease in Mexico: an analysis of geographical distribution during the past 76 years-a review. Mem Inst Oswaldo Cruz 101: 345-354.

10. Guzman-Bracho C, 2001. Epidemiology of Chagas disease in Mexico: an update. Trends Parasitol 17: 372-376.

11. Lopez-Cardenas J, Gonzalez Bravo FE, Salazar Schettino PM, Gallaga Solorzano JC, Ramirez Barba E, Martinez Mendez J, Sanchez-Cordero V, Peterson AT, Ramsey JM, 2005. Fine-scale predictions of distributions of Chagas disease vectors in the state of Guanajuato, Mexico. J Med Entomol 42: 1068-1081.

12. Dumonteil E, 1999. Update on Chagas' disease in Mexico. Salud Publica Mex 41: 322-327.

13. Cortez MR, Emperaire L, Piccinali RV, Gurtler RE, Torrico F, Jansen AM, Noireau F, 2007. Sylvatic Triatoma infestans (Reduviidae, Triatominae) in the Andean valleys of Bolivia. Acta Trop 102: 47-54.

14. Pizarro JC, Lucero DE, Stevens L, 2007. PCR reveals significantly higher rates of Trypanosoma cruzi infection than microscopy in the Chagas vector, Triatoma infestans: high rates found in Chuquisaca, Bolivia. BMC Infect Dis 7: 66.

15. Blanco SB, Segura EL, Cura EN, Chuit R, Tulian L, Flores I, Garbarino G, Villalonga JF, Gurtler RE, 2000. Congenital transmission of Trypanosoma cruzi: an operational outline for detecting and treating infected infants in north-western Argentina. Trop Med Int Health 5: 293-301.

16. Coll-Cardenas R, Espinoza-Gomez F, Maldonado-Rodriguez A, Reyes-Lopez PA, Huerta-Viera M, Rojas-Larios F, 2004. Active transmission of human Chagas disease in Colima Mexico. Mem Inst Oswaldo Cruz 99: 363-368.

17. Guzman-Bracho C, Lahuerta S, Velasco-Castrejon O, 1998. Chagas disease. First congenital case report. Arch Med Res 29: 195-196.

18. Sosa-Estani S, 2005. Congenital transmission of Trypanosoma cruzi infection in Argentina. Rev Soc Bras Med Trop 38 (Suppl 2): $29-32$.

19. Moncayo A, 2003. Chagas disease: current epidemiological trends after the interruption of vectorial and transfusional transmission in the southern cone countries. Mem Inst Oswaldo Cruz 98: 577-591.

20. Velasco-Castrejon O, Valdespino JL, Tapia-Conyer R, Salvatierra B, Guzman-Bracho C, Magos C, Llausas A, Gutierrez G, Sepulveda J, 1992. Seroepidemiology of Chagas disease in Mexico. Salud Publica Mex 34: 186-196.

21. Pan American Health Organization, 2006. Acuerdos y recomendaciones de la IXa reunión anual de la IPCA (Guatemala, 11-13 September 2006), 2007: 5.

22. Pan American Health Organization, 2004. XIIa reunión de la comisión intergubernamental del cono sur para la eliminación de triatoma infestans y la interrupción de la transmisión transfusional de la tripanosomiasis americana (INCOSUR/Chagas, March 26-28, 2003), 2007: 24. Available at: http:// www.paho.org/Spanish/AD/DPC/CD/dch-XII-INCOSUR-inffinal-arg.pdf. Accessed December 3, 2007.

23. Zaidemberg M, Spillmann C, Carrizo Páez R, 2004. Control de 
Chagas en la Argentina. su evolución. Rev Arg de Cardiol 72: 375-380.

24. Roddy P, Goiri J, Flevaud L, Palma PP, Morote S, Lima N, Villa L, Torrico F, Albajar-Vinas P, 2008. Field evaluation of a rapid immunochromatographic assay for detection of Trypanosoma cruzi infection by use of whole blood. J Clin Microbiol 46: 2022-2027.

25. Russomando G, de Tomassone MM, de Guillen I, Acosta N, Vera N, Almiron M, Candia N, Calcena MF, Figueredo A, 1998. Treatment of congenital Chagas' disease diagnosed and followed up by the polymerase chain reaction. Am J Trop Med Hyg 59: 487-491.
26. Garcia A, Bahamonde M, Verdugo S, Correa J, Pastene C, Solari A, Tassara R, Lorca M, 2001. Trypanosoma cruzi transplacental infection: situation in Chile. Rev Med Chil 129: 330-332.

27. Torrico F, Alonso-Vega C, Suarez E, Rodriguez P, Torrico MC, Dramaix M, Truyens C, Carlier Y, 2004. Maternal Trypanosoma cruzi infection, pregnancy outcome, morbidity, and mortality of congenitally infected and non-infected newborns in Bolivia. Am J Trop Med Hyg 70: 201-209.

28. Brutus L, Schneider D, Postigo J, Delgado W, Mollinedo S, Chippaux JP, 2007. Evidence of congenital transmission of Trypanosoma cruzi in a vector-free area of Bolivia. Trans $R$ Soc Trop Med Hyg 101: 1159-1160. 